\title{
Exploration on the Design and Development of Micro Mobile Learning Resources
}

\author{
Xiuli Yuan ${ }^{1, a}$, Guangfeng Guo ${ }^{2, b}$ \\ ${ }^{1}$ Department of Information Science and Technology, Baotou Teachers' College, Baotou, 014030, \\ China \\ ${ }^{2}$ Department of Information Science and Technology, Baotou Teachers' College, Baotou, 014030, \\ China \\ aemail: m13171289034@163.com, bemail:guoguangfeng@163.com
}

Keywords: Micro Mobile Learning; Micro Mobile Learning Resources; Design; Development

\begin{abstract}
Mobile Learning as a way of learning emerges as the times requires. In order to ensure the effectiveness of Mobile Learning, this paper analyses and expatiates the design theory, design principles, design processes, learning contents and information sources of designing micro mobile learning resources, and introduces the resource development platform and implementation methods, presents a feasible design and development ideas. It also provides a reference for the research of micro mobile learning.
\end{abstract}

\section{Introduction}

Along with the in-depth development of teaching theory, learning theory, communication theory and the broad application of the mobile telecommunications technology, pervasive computing technology, multimedia and network technology and other information technology in the educational field, Mobile Learning being a new learning style appeared on the scene, which is meeting the needs of individual learning. With mobile devices and wireless network, Mobile Learning that carries out the education activities and transfers the information of education can occur at any time and in any place. This kind of learning mode relying on mobile devices provides possibility for lifelong learning [1].With the wide use of portable mobile terminal, Mobile Learning meet the demand of "anytime, anywhere, carrying" to study. Thus, it has many advantages of convenience, flexibility, high efficiency, and mobility.

Learning terminals and wireless communication network technology are the material basis for Mobile Learning. At present, a variety of mobile learning terminals can be used, such as smart phones, PDA, learning machines with wireless communication module, also MP3, MP4, e-books and other equipment in the off-line learning. 3G (the third-generation communication technology) combined with wireless communication, Internet and multimedia communication technology can provide high-speed data services with the rate in more than a few hundred kbps. Not only can it process images, music, video and other forms of medias, which also provides, such as webpage browsing, telephone conference, e-commerce and other services, and promotes the development of Mobile Learning based on the mobile phone.

As being a kind of learning morphology, Micro-learning is developing from the processing of the theory of information technology, learning theory (especially the Connectivism learning theory), and communication theory, and being focused in the educational field. "micro" can be micro, small, light and other means, reflected in the micro morphology of learning content, learning media, and learning time. Lindner proposed that the design of Micro-learning needs to consider the following important features: simplicity, driven behavior, edge, process, participation and open features [2].

Therefore, the theory of "micro mobile learning" pays special attention to the miniaturization of learning content and learning media, and the most of its research focus on tiny, small modular, episodic learning content design and the learning platform development based on the micro media. The mobile communication tool is often the typical micro carrier of micro mobile learning. So, learners in a moving state of Microlearning are the effective combination of modern technology and 
new learning mode.

\section{Design of Micro Mobile Learning Resources}

The micro mobile learning resources are to meet learning needs and their design is one of the most important parts of mobile learning design. Its design process must consider the following contents:

\section{A. The main theoretical basis}

1)Constructivism: The basic view of constructivism is human knowledge is only an interpretation of the objective world; learning is to construct the knowledge through negotiation in the community; the learners are active constructors of the significance of knowledge, Constructivism emphasizes situational knowledge application, and treats knowledge and people with the dialectical development view. [3]

Constructivism learning theory makes analysis of the process of learning behavior from the learner's internal factors, emphasizing the importance of individual exploration of knowledge meaning, points out that learning is a process of discovering things connected individual, situational, dialogue, consultation. Construction learning is very important for learners. Its characteristics are the focus of micro mobile learning, and this theory supports the effective micro mobile learning.

2)Connectivism: As George Siemens pointed out, Connectivism is a kind of chaos, network, complexity and self-organization theory to explore the whole [4].This theory explains: learning is in a cloudy network, a process of core elements migration. The migration is not fully under the control of learner himself; learning (actionable knowledge) can exist in outside our own organization or database entities; learning is the different links of information sets which can let us have the opportunity to learn more knowledge. These relationships are more important than our own knowledge.

Connectivism from the external of learners analyses the process of learning behavior, emphasizing that learning is the process of constructing individual society and knowledge network. They also point out that learning is a process where individual explores things outside himself. (Connection does not exclude the internal connection). Node, network, organization, relationship to the learners has very important significance. Its characteristic is the focus of micro mobile learning, and this theory also supports the effectiveness of mobile learning.

\section{B. Design principles}

The design of micro mobile learning resources rests on the principles of teaching resource design and combines with the rules and characteristics of mobile learning to design.

1) Simple design principles: The physical characteristics of Mobile learning terminals and network equipment as well as the characteristics of micro mobile learning determines the learning resource design; the content should be concise, comprehensive, and more general to meet the needs of visual, readable resources and micro mobile learning.

2) Principle of diverse design: Considering the learning needs (different initial ability, different learning styles, learning objectives), different features of learning content, the limitations of mobile learning device as well as the internal and external continuous connection etc, The content of mobile learning resources should be diverse, then situation of resource application should be diversified, resource form should be diversified to meet the effective learning needs.

3) Design principles of fragment focusing: The Stanford University Laboratory (SLL) through the study found that Mobile Learning is very susceptible to outside influence, so learners can not keep their attention focused for a long time. Therefore, the form of micro mobile learning requires the resource information should be divided or organized into small fragments, and expressed in various forms of focus, in order to make learners have intensive and deep study of learning content.

4) Functional design principles: The presenting form of resource information is fragmented, so it is necessary to give the students recommendations during their learning process, at the same time, related resource information is well organized .Therefore, the resource information can be in the 
concept map (knowledge map), in the form of expression in order to reflect the relationship between them, in order to let learners well understand the learning content and share and exchange more information resources in the social network of mobile learning resource design.

\section{Design process}

The "Instruction Design" theory provides theoretical foundation for developing mobile learning resources. This theory holds that teaching relate to learners, learning contents, learning targets, learning activities and learning situation. So, the suggested elements must be considered in developing mobile learning resources.

Ronghuai Huang put forward the development process of mobile learning resource design from the macroscopic view, which is proposed to consist of nine steps: the learning objectives and content, structure design, interface design, navigation design, prototype implementation, material preparation, resources development, resources integration and testing/modify. This model comprehensively describes each link of design and development on the macro mobile learning resources, this paper makes in-depth exploration on the basis of that[5].

\section{The design of learning contents}

The characteristics of micro mobile learning determine the characteristics of content design. Arroyo thinks Microlearning is focusing the content of Microlearning [6]. We can understand that micro-content is suitable for learning independent fragment content. Learning content can be divided into two categories of theoretical knowledge and skills; from the organization manner of speaking, the micro mobile learning content can be also divided into two types: the various forms of learning content focused single point of learning content and the mini-course with clear teaching objectives, shorting content and focused on a topic (in a mini-class students can only learn a knowledge point or a skill point).

\section{E. Sources of information}

Based on the learning needs, different characteristics of learning content, the limitations of the mobile learning devices as well as the internal and external connections of learning ways, information not only considers the relative independence of micro mobile learning content, but also the hided correlations among the information content. Therefore, it is intended to construct continuous knowledge structures for students. The following figure (Figure 1) shows formation source state of a mini-class.

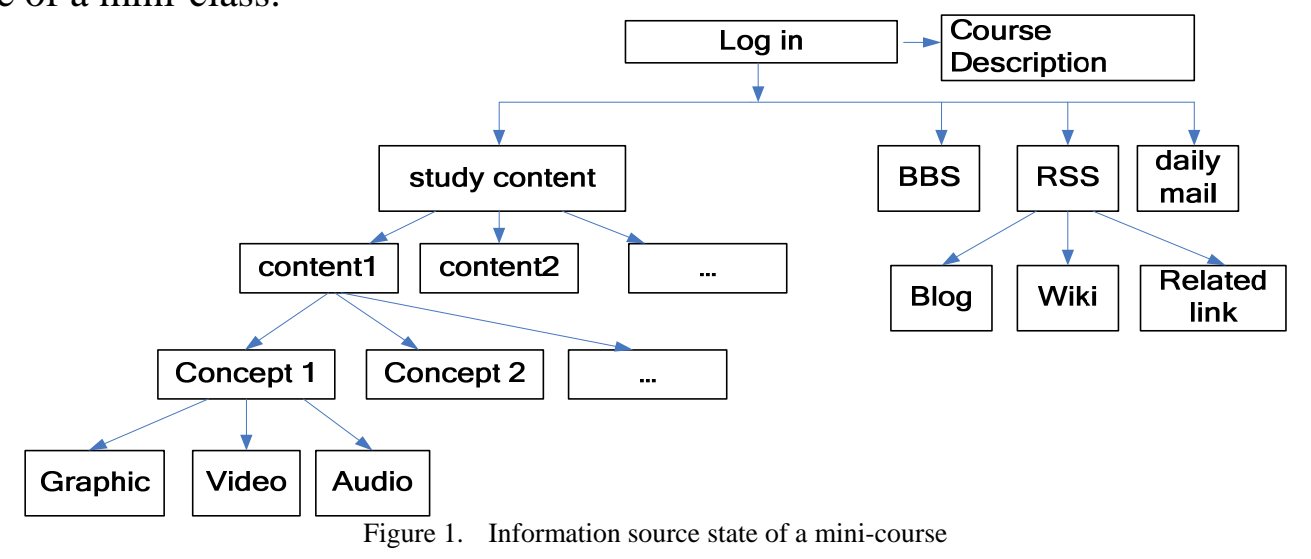

\section{The Development of Micro Mobile Learning Resources}

We take smart mobile phones as learning terminals for an example to introduce the content. In developing the system of micro mobile learning resources, we develop and build the mini-course resource platform providing learning resource distributing services, and learners install the APP (mobile phone application) about learning micro course into smart mobile phones. Learners run the APP, and input their account information, and thought the platform certification they can begin to 
learn the micro course from the platform.

\section{A. Development platform and selection of tools}

1) System structure: The mini-course resource platform consists of a management server for mini-course resources, a streaming media server, some management workstations (see Figure 2). The management server for mini-course resources stores all account information and learning resource information(except video information), and provide the service of authentication and resource distribution and downloading the APP for Microlearning; The streaming media server stores streaming media video resources and provides the service of streaming video distribution. The resource management workstations manage and maintain the two above-mentioned servers. The two servers connect to the Internet.

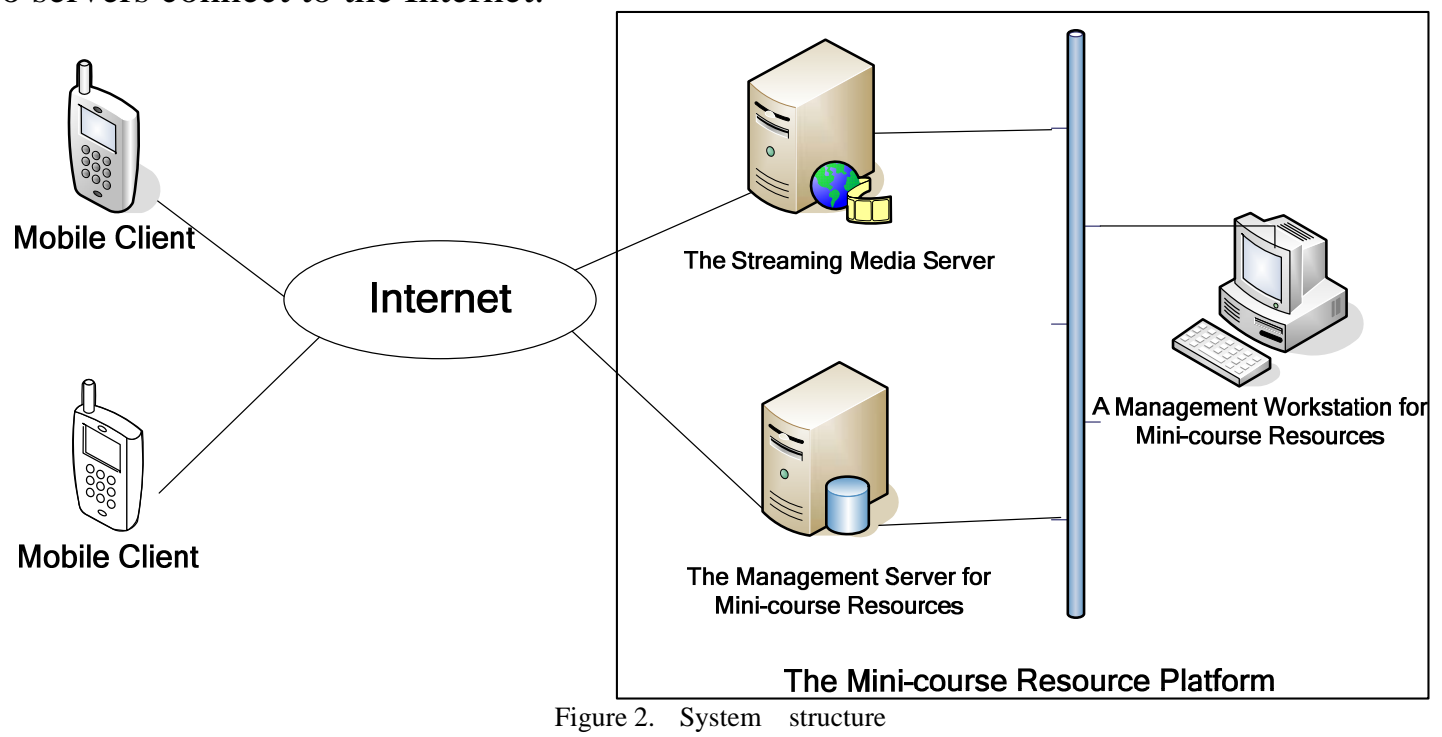

Learners use smart mobile phones and connect to the Internet to download the APP for learning micro course from the management server. After installation, learners run the APP, input their account and passwords. After successful authentication, the learners can select one or more topics and study their selected courses.

2) The development platform: In the development of the mini-course platform, the technologies such as Struts2, Hibernate, Spring, Json are applied, and Microsoft SQL Server2005 provides data services. The mini-course platform supplies data stream in Json for The APP (installed on the mobile phones) through Servlet, and provides resource management services for the management workstations through Web. In the streaming media server, live555 (a streaming media service of open source solution) is used, which supports more streaming media transmission protocols such as RTSP, RTP/RTCP and SIP. The APP for micro mobile learning based on Android 2.2, JAVA JDK 1.6、 Eclipse 3.6、ADT 0.9.7 (Android Development Tools)、 android SDK Tools R6 are used as the development tool.

\section{B. Implementation methods}

1) Presentation of the curriculum content: The curriculum content includes text, images, audio or video, and related links of Blog, Wiki and websites (such as Baidu Encyclopedia). The layout and content of the curriculum content using SMIL (Synchronized Multimedia Integration Language) is described in the form of a document stored in the platform of mini-course resources. Other information such as the themes, keywords, related links of Blog, Wiki and websites, creators and create time is stored in the database of Microsoft SQL Server 2005.

2) Data format of the streaming media: The videos in curriculum content uses streaming media technology, using live555, the H.264 encoding and decoding technology in a certain bandwidth condition, so learners can play related videos while downloading course videos without waiting. Because H.264/AVC can greatly improve the coding efficiency, compared to all previous video coding standards (such as ITU-T H.263 and MPEG-4), it can reduce the 1/3 to the $1 / 2$ rate with the 
same code quality, and has higher compression ratio and better wireless network adaptability, so it has more and more extensive application in the video communication and data storage field [7]. Therefore, the mobile streaming media transmission of video data is compressed with the H.264 compression algorithm, in order to transmit better images and videos with low bandwidth coding for wireless transmission (15-25kbs), or use less bandwidth transporting the same quality of video.

3) Development of the APP: The development of APP is based on Android 2.2 operating system, and its development environment is built on PC, based on Windows XP, using JAVA JDK 1.6, Eclipse 3.6, ADT (Android Development Tools) 0.9.7, Android SDK Tools R6 as development tools.

The mobile phone decoding the H.264 video generally depends on the hardware. To break this limitation in development, adopting the method of software decode is adopted to decode the H.264 video. The streaming media solution "FFmpeg" (a open source audio video solution based on Linux kernel) is cutted down and migrated to the Android platform.

\section{Conclusion}

Practice shows that the effect of micro mobile learning especially as an assisted learning style is good in accordance of above ideas.

The design and development of micro mobile learning resources is one of the main research directions of micro mobile learning resources, it directly determines whether the micro mobile learning environment better support the mobile learning activities. Different forms of the micro mobile learning provide a variety of learning style support in the micro mobile learning. However, its existing research also need a great breakthrough, like how to achieve efficient learning for learners to provide pushing resource service, how to make the knowledge, skill points more effectively and continuously connected. Only the micro mobile learning resources are designed and developed more deeply satisfying, learners though the mobile learning efficiently access to more knowledge and skills.

\section{Acknowledgement}

In this paper, the research was sponsored by the project of Inner Mongolia Province Education Department (Project No. NJZY11172).

\section{References}

\section{REFERENCES}

[1] Ronghui Huang. Mobile Learning-Theory•status•trend [M]. Beijing: Science Press, 2008.1-10.

[2] Martin Lindner, Peter A. Bruck. "Micromedia and Corporate Learning", Proceedings of the 3rd International Microlearning 2007 Conference [M].Innsbruck University, 2007. 100-105.

[3] Cuie Chen. The Study on the Instruction Design of Mobile Learning Resource, in press.

[4] Gerge Siemens. Connectives: A Learning Theory for the Digital Age [J]. Instructional technology \& Distance learning. Pittsburgh. 2005(1)3-10.

[5] Ronghui Huang. Mobile Learning-Theory•status•trend [M]. Beijing: Science Press, 2008.50.

[6] S. Arroyo. A Semantic Service-based micro-learning framework[A]. Microlearning Conference 2006[C].Innsbruck University.2006.260-272.

[7] Kaijiang Feng. mobile streaming media technology in the field of digital video communication and storage[J]. New Media. 2007. 35-37. 